\title{
A case study of a conservation flagship species: the monarch butterfly
}

\author{
Stephanie D. Preston ${ }^{1}$ - Julia D. Liao ${ }^{1} \cdot$ Theodore P. Toombs $^{2} \cdot$ Rainer Romero-Canyas $^{2}$. \\ Julia Speiser ${ }^{1} \cdot$ Colleen M. Seifert $^{1}$ (D)
}

Received: 30 August 2020 / Revised: 23 March 2021 / Accepted: 12 April 2021 /

Published online: 4 May 2021

(c) The Author(s) 2021

\begin{abstract}
What makes a flagship species effective in engaging conservation donors? Large, charismatic mammals are typically selected as ambassadors, but a few studies suggest butterflies - and monarchs in particular - may be even more appealing. To gather more information about people's responses to monarchs, we conducted an empirical study of member submissions to a successful conservation campaign, the Monarch Story Campaign, conducted by the Environmental Defense Fund (EDF). The set of 691 stories along with their associated demographic and donation data was analyzed in a mixed-methods study using qualitative analysis and tests of association. The results showed that people often described encounters with monarchs in childhood and as adults. They expressed strong, positive emotions, and lauded the monarch's beauty and other "awe-inspiring" qualities and expressed wonder at their lifecycle (i.e., metamorphosis and migration). They also raised conservation themes of distress at monarch loss, calls for action, and caretaking, such as being "fragile" and "in need." Sharing personal encounters was associated with current efforts to save the species and more past financial donations, while a second pattern tied more donations to awe at the monarch's mass migration. These results imply that conservation campaigns built around species people encounter may build lifelong awareness, concern, and actions towards conservation.
\end{abstract}

Keywords Conservation - Conservation marketing - Environmental psychology, environmental attitudes $\cdot$ Mixed methods $\cdot$ Flagship species $\cdot$ Monarch butterflies

Communicated by Peter Bridgewater.

Colleen M. Seifert

seifert@umich.edu

1 University of Michigan, Ann Arbor, USA

2 Environmental Defense Fund, New York, USA 


\section{Introduction}

Monarch butterflies (Danaus plexippus) are among the most popular insect species in the world, and are easily recognizable in gardens and fields across North America (Oberhauser et al. 2018). Articles about monarchs appear frequently in the popular press; for example, the New York Times published (on average) one each month from 1995 to 2015 (cf. Gustafsson et al. 2015). In the 1950s, Fred and Norah Urquhart chose monarchs for the first citizen science research project on, "Where do monarchs go in the winter?" (Urquhart and Urquhart 1976). Monarch migration and overwintering sites now draw thousands of ecotourists each year (Lemelin and Jaramillo-López 2019; Lemelin et al. 2019). Thanks to school programs and large-scale monitoring projects, public awareness of monarchs has grown over generations who are interacting with monarchs "in the wild" (Young-Isebrand et al. 2015; Gustafson et al. 2015; Lewandowsky and Oberhauser 2017).

But since the turn of the century, wildlife habitat loss, herbicide use, and climate change have caused a rapid decline in the monarch population (Thogmartin et al. 2017). In 2014, U.S. President Barack Obama requested the establishment of a federal strategy to save the monarch, which initiated a status assessment by the U.S. Fish and Wildlife Service (White House 2014). Concurrently, a wide array of longstanding and new conservation groups (from local to national in scope) have coalesced around this cause through a new organization: The Monarch Joint Venture (Monarch Joint Venture 2020). Monarch conservation efforts also align with sustainable farming practices to address habitat, water quality, and erosion through changes like vegetated field buffers, which also provide food for migrating butterflies (Gustafsson et al. 2017). Based on this unprecedented coalition of conservation activity, the monarch came to represent the decline of biodiversity and broader environmental issues across North America (Gustafsson et al. 2015, 2017).

The monarch's recovery will require an unprecedented collaborative conservation effort (Jepsen et al. 2015). Efforts to save the species from extinction will be expensive, as feeding habitats must be restored across a wide swath of North America through planting milkweed and nectar-producing plants (Thogmartin et al. 2017) and through changes to agricultural policies (Nail et al. 2015). These efforts will require large financial contributions and broad societal support, from agriculture, industry, citizens group, conservation organizations, and all levels of government, which will likely cost hundreds of millions of dollars (Thogmartin et al. 2017). Conservation organizations rely upon varied sources of financial support, including public funding, private donors, foundations, and individual annual memberships. Without strong public support, these funding sources may fall short of what is needed to save the monarch.

Fortunately, the general public, scientists, and conservationists appear to be rallying and uniting to save the monarch (Gustafsson et al. 2015). Efforts to save the monarch also benefit from the fact that it is a well-known and beloved creature. For example, the monarch butterfly is the only insect described as "iconic" by the National Wildlife Federation, the Natural Resource Defense Council, and the World Wildlife Fund (Horsley et al. 2020). What is special about the monarch? Can the monarch's popularity be applied to generate broader conservation support? 


\section{Flagship species}

Species surrogacy is a conservation fundraising strategy (Simberloff 1998) where a single "flagship" species is marketed in conservation magazines and environmental nongovernmental organization (ENGO) campaigns to the general public, generating interest and revenue (Verissimo et al. 2011). Flagship species draw people's interest; for example, people playing an online game donated more to campaigns featuring flagship (e.g., elephants, polar bears, and tigers) than non-flagship (e.g., frogs, cods, and stoneflies) species (Thomas-Walters and Raihani 2017). Most flagship campaigns employ large mammals or charismatic megafauna due to their popularity with donors (Caro et al. 2004; MacDonald et al. 2015); for example, polar bears have become icons for climate change (Born 2019; World Wildlife Fund 2020). Because of this focus, the majority of conservation publications feature mammals, while invertebrates representing over $90 \%$ of species are underrepresented (Barua 2011). Flagship species can serve as "ambassadors" by drawing attention to biodiversity within their distribution (Bennett et al. 2015; Macdonald et al. 2017). However, the assumption that the wealth spreads to other species may be mistaken, as these campaigns may suggest that other species are less valuable (Douglas and Winkel 2014), and 61\% of flagship campaigns raised funds for only the target species (Smith et al. 2012).

Researchers have called for a more rigorous and objective approach to selecting flagship species by using marketing research to compare people's preferences across species (Verissimo et al. 2011). Flagship species possess greater perceived charisma, larger geographical distribution, more threatened conservation status, better visibility, and larger body size (Barua, 2012). An empirical study with over 1500 people from five continents assessed the relative charisma of different mammals and found that: (1) large body size is a key selection feature; (2) big cats and primates are most preferred; and (3) the tiger (Panthera tigris) was the top species by a wide margin (Macdonald et al. 2015). Research funding shares this bias, as more money is allocated to larger species without considering conservation status or geographic range (Tensen 2018). Conservation communications and environmental non-governmental organizations (ENGO) also show this body size bias (Barua 2011; Horsley et al. 2020). Preferences are also predicted by familiarity (Schlegel and Rupf 2010), at both global and local levels (Macdonald et al. 2015). Flagship species are also defined by their aesthetic appeal or "cuddliness," and these features fit a broader range of species (Smith et al. 2012). Despite these findings, theorists note that we have little understanding about, “... why certain species have appeal, galvanize action, and have staying power" to influence conservation outcomes (Jepson and Barua 2015, p. 95).

\section{Butterflies as flagship species}

Based on the fact that preferred flagship species are usually large mammals with forward facing eyes (Smith et al. 2012), the monarch would appear to be a poor choice as a campaign focus. However, they are beautiful, fairly familiar, and threatened, which suggests that they are a good candidate for an overlooked "Cinderella species," as defined by Smith and colleagues (2012). It is also beneficial for the monarch that they tap deeply into North American cultural concepts and associations, allowing them to speak for broader conservation goals (DeMello 2012; Jepson and Barua 2015). The monarch has been identified as a 
socially constructed "icon" that connects public, scientific, and conservationist interests as a symbol of broader environmental concerns in the U.S. (Gustafsson et al. 2015; 2017).

However, to our knowledge, there is little empirical evidence to support this culturally constructed view of people's thoughts, feelings, and associations in response to butterflies. A U.K. study found that people reported higher levels of benefit and satisfaction with charismatic species like birds and butterflies than with beetles and bugs (McGinley et al. 2017). Comparisons across species show that along with mammals, people prefer butterflies and birds over reptiles, insects, and amphibians (Schlegel and Rupf 2010; Roberge 2014), with butterflies the most favored animal in the study (Schlegel and Rupf 2010). A study of invertebrate species in northeast India found preferences for butterflies, honeybees, and dragonflies over competitors because of their aesthetic appeal and harmlessness (Barua et al. 2012). However, people in that study also had negative views of caterpillars, attributing harm and economic damage to them, and only $63 \%$ said butterflies benefitted humans.

These findings suggest that butterflies have potential as flagship species for conservation programs, but we must better understand people's responses to them. An empirical field study examining people's perceptions, attitudes and associations with monarchs may suggest how they may influence conservation engagement. While the monarch's plight has clearly grabbed broad attention (Gustafsson et al. 2017), the question of whether and why it may spur donations for conservation programs remains.

\section{The monarch as flagship species}

To examine why people are drawn toward monarchs and whether these attributes promote conservation aid, we conducted a case study of a conservation campaign by Environmental Defense Fund, Inc. (EDF), an international ENGO that has publicized the decline of monarchs and worked closely with agricultural groups to implement on-the-ground conservation projects (Environmental Defense Fund 2020). Like many other organizations, EDF is reliant upon donations to fund its actions, and fundraising from private donors requires contact with the public through social media, their website, and email campaigns. In a recent campaign - the "Monarch Story Campaign"-EDF created a website focused on the monarch butterfly (EDF 2018). Through EDF email lists, members were encouraged to visit the website to, "Tell your Monarch story" by writing about, "What does the Monarch mean to you?" EDF members were strongly engaged by The Monarch Story Campaign, as measured through website traffic and a higher than usual number of donations.

While this online engagement was high, it is unclear why. Monarch butterflies are renowned for their beauty; on the campaign website, appealing images signaled opportunities to donate (Nail et al. 2015; Gustafson et al. 2015). Monarchs are also familiar to people in the United States, and people protect familiar species (Schlegel and Rupf 2010). Monarchs may also benefit from their link to familiar places, which creates positive cultural associations (Jepson and Barua 2015). People also have personal experiences with monarchs or their migration, which creates memories that may motivate conservation (Bandura 1999, 2001, 2018). School programs and science projects like raising and releasing monarchs also expose people directly to the species (Young-Isebrand et al. 2015; Gustafson et al. 2015). The monarch also has a unique life-history including metamorphosis, massing, and annual migration crossing national borders in North America (Gustafsson et al. 2015; Simaika and Samways 2018), heightening their political and geographic prominence.

In addition, the monarch symbolizes cultural values, including beauty, natural wonder, scientific discovery, conservation imperatives, and civic duty (Gustafson et al. 2015, 2017). 
These cultural themes may create a shared, "animal as constructed" (see DeMello 2012) view of monarchs without first-hand experiences. For example, their metamorphosis from caterpillar to butterfly has been tied to spiritual and religious symbolism, such as the loss of loved ones and their souls returning on the Day of the Dead (Gustafsson et al. 2015). Finally, people may want to help the monarch because they share features with helpless neonates in need, signaling caregiving responses in human evolution (Preston 2013). The monarch's threatened status, delicate and attractive appearance, and helplessness as a prey species may potentiate people's motivation to help. Thus, there are many possible reasons that people may want to become involved in monarch conservation, but little evidence about the factors responsible for their engagement.

For these reasons, we conducted a case study of the EDF Monarch Story Campaign as a distinct instance of conservation programs (Abercrombie et al. 1984; Greene and Shepard 2003; Flyvbjerg 2011). Our research goal was to identify why people engaged with this campaign by observing how their open-ended stories reflected their responses to monarchs. Our critical case approach included a qualitative analysis with an interpretivist epistemological perspective (Flyvbjerg 2001, 2006; Patton 2002), recognizing that the outcomes depend on the context, and the context is integrated into the analysis of findings (Creswell 1994; Patton 2002). This qualitative analysis of emergent themes in submitted stories was followed by statistical analyses of relationships among themes, conservation actions, and demographic variables. This mixed-methods approach (Creswell 2017) was aimed at determining which associations to monarchs inspired people to participate in the campaign. We hypothesized that monarch engagement would be particularly tied to their beauty, to their familiar (but unique) life history which people directly observe, and to the drive to take care of the endangered, helpless, and fragile.

\section{Method}

\section{Dataset}

EDF sent two separate email prompts to their list of prior donors. The first offered a detailed Monarch Story from a staff member (Appendix A) and invited the recipient to follow a link to an EDF web page where they entered and submitted their story in an open text response box (Fig. 1) and (optionally) entered their name and email. Four months later, a follow-up email

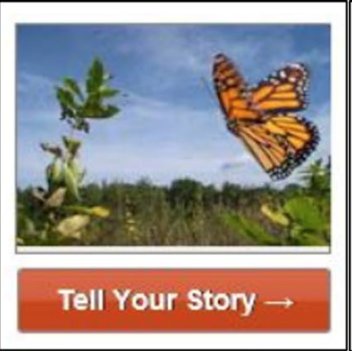
What's Your Monarch Butterfly Story?
Habitat loss and increased use of pesticides are putting the milkweed the monarch depends upon for survival at risk-and the butterflies are paying the price.
That's why we here at EDF are joining the effort to

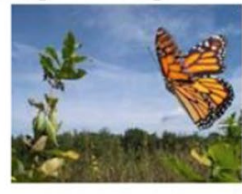 protect and restore habitat for monarch butterfly. As we start this program, we want to know: What does the monarch mean to you?

Fig. 1 The EDF Monarch Story Campaign materials included a staff member's story in each of two emails. Images in the emails (left) linked to the EDF campaign web page with a story prompt (right) 
invited the same email recipients to revisit the site to view anonymized story submissions that were pinned to a national map onto which they could add their own story:

"Monarch butterflies - just hearing the words brings a beautiful, black and orange miracle of nature fluttering through your mind. For me, the monarch was one of my first connections to nature - potentially what led me to EDF all these years later. And when I asked for your Monarch stories, you made it clear: the Monarch has played a crucial role for you, as well.

For some, it's a connection to a lost loved one-a reminder of times you shared. For others, it's proof that we can always metamorphose, always become better versions of ourselves. And for many, it's a passion, a creature you're working hard to bring back from the brink."

Further information about monarchs and EDF campaigns was available on EDF webpages.

The dataset for the study included the 691 monarch butterfly stories submitted by members of the public to the EDF website over the five-month campaign. The stories' length averaged 453.66 characters $(S D=391.90)$, with a range from 6 (e.g., one response include a single word, "beauty") to 4,422 characters. Some stories were entered into the EDF web page anonymously, but the majority included email addresses. EDF researchers retrieved linked demographic data for 517 of the entries through these emails. This demographic data (ethnicity or race) included gender (74\% female with no nonbinary reported), age (75\% ages 45-64), education (78\% college graduates), homeowner status (78\% homeowners), household income (median 50,000 to 75,000), net worth (median 250,000 to 500,000), location (e.g., rural vs. urban), and donation history. The remaining 174 stories were either anonymous or did not match past donor email addresses. Importantly, no data was available for donations in direct response to the Monarch Story campaign; consequently, donor characteristics from past EDF contributions served as an index of broader environmental giving.

\section{Qualitative coding of themes}

In order to document the content described in the stories, we created a qualitative codebook beginning with candidate themes adapted from prior studies as described above. Following Creswell (2017), the stories were also analyzed for emergent themes from an initial review of a random subset of 100 stories, followed by an iterative, detailed revision of the set of codes to improve their accuracy and remove duplication (Boeij 2002). The codebook was refined to 43 themes, and three coders independently scored a subset of 100 stories for the presence of each theme. Any discrepancies were discussed, and the coding criteria clarified or adjusted as needed. The coders then proceeded to independently score the remaining 591 stories. Statistical tests showed high interrater agreement for each individual theme code (all 43 had agreement above 0.87) (shown in Table 1). The three coders discussed any differences to agreement to determine the final codes. We also coded the two emails sent out by EDF for any of the themes and found that 20 of 43 themes (46\%) appeared in at least one of the two Monarch Story campaign emails. 
Table 1 Identified themes $(n=43)$ in order of frequency across the set of 691 stories

\begin{tabular}{|c|c|c|c|c|c|}
\hline Rank order & Identified themes $(n=43)$ & $\begin{array}{l}\text { Interrater } \\
\text { agreement (\%) }\end{array}$ & EDF email & Frequency $(\%)$ & $\begin{array}{l}\text { Number of } \\
\text { stories }\end{array}$ \\
\hline 1 & Aesthetic beauty & 87.4 & $1 \& 2$ & 35.9 & 248 \\
\hline 2 & Planting to feed & 90.5 & $1 \& 2$ & 25.2 & 174 \\
\hline 3 & Childhood experiences & 92.5 & 1 & 23.4 & 162 \\
\hline 4 & Joy, happy, delight & 80.8 & 1 & 22.9 & 158 \\
\hline 5 & Awe-inspiring, wonder & 83.5 & 1 & 18.8 & 130 \\
\hline 6 & Experience with reduction & 90.5 & $1 \& 2$ & 17.7 & 122 \\
\hline 7 & $\begin{array}{l}\text { Experience with metamor- } \\
\text { phosis }\end{array}$ & 91.3 & $1 \& 2$ & 17.1 & 118 \\
\hline 8 & $\begin{array}{l}\text { Experiences with colony or } \\
\text { mass }\end{array}$ & 92.3 & & 16.9 & 117 \\
\hline 9 & Sadness for reduction & 92.5 & & 14.5 & 100 \\
\hline 10 & Raised butterflies & 92.9 & 1 & 12.0 & 83 \\
\hline 11 & Experience with a loved one & 90.3 & 2 & 12.0 & 83 \\
\hline 12 & Experiences with migration & 92.6 & $1 \& 2$ & 11.1 & 77 \\
\hline 13 & Call for collective actions & 91.5 & $1 \& 2$ & 10.3 & 71 \\
\hline 14 & Knowledge of reduction & 88.3 & $1 \& 2$ & 10.0 & 69 \\
\hline 15 & Seen in the yard or garden & 89.5 & & 9.0 & 62 \\
\hline 16 & Magic, magical, miracle & 97.1 & $1 \& 2$ & 8.8 & 61 \\
\hline 17 & Free-flying, freedom & 92.8 & 1 & 8.4 & 58 \\
\hline 18 & Pesticide harm & 95.5 & 1 & 8.1 & 56 \\
\hline 20 & Other conservation actions & 89.9 & & 7.7 & 53 \\
\hline 21 & Spring (season) & 96.2 & $1 \& 2$ & 7.4 & 51 \\
\hline 22 & Monarch lifecycle & 93.6 & 1 & 7.2 & 50 \\
\hline 23 & Landed on me or other & 97.3 & & 5.9 & 41 \\
\hline 24 & Balance, importance & 95.5 & & 5.1 & 35 \\
\hline 25 & Spiritual or lost love & 98.3 & 2 & 4.9 & 34 \\
\hline 25 & Experience of loss & 98.3 & 2 & 4.9 & 34 \\
\hline 26 & Protected/saved/helped & 96.8 & & 4.5 & 31 \\
\hline 27 & God, God's creation, gift & 98.8 & & 4.3 & 30 \\
\hline 28 & Frail, delicate, fragile & 99.0 & & 3.9 & 27 \\
\hline 29 & Harbinger of decline & 96.5 & & 3.6 & 25 \\
\hline 30 & Amazing abilities & 90.8 & $1 \& 2$ & 3.6 & 25 \\
\hline 31 & Not using pesticides & 99.1 & & 3.6 & 25 \\
\hline 32 & Science class or school & 94.5 & 1 & 3.5 & 24 \\
\hline 33 & Corporations and money & 98.3 & & 3.2 & 22 \\
\hline 34 & Anger at damage & 97.1 & & 3.0 & 21 \\
\hline 35 & Metamorphosis knowledge & 97.3 & $1 \& 2$ & 2.6 & 18 \\
\hline 36 & Strength, resilience & 97.5 & & 2.6 & 18 \\
\hline 37 & Role as pollinator & 99.4 & & 2.5 & 17 \\
\hline 38 & Learned in science class & 100.0 & & 2.2 & 15 \\
\hline 39 & Presence in art or poems & 97.8 & & 2.0 & 14 \\
\hline 40 & Self and metamorphosis & 98.7 & 2 & 1.5 & 10 \\
\hline 41 & Precious or treasured & 99.7 & & 1.5 & 10 \\
\hline 42 & Mass migration knowledge & 99.3 & & 0.9 & 6 \\
\hline 43 & Life-changing & 99.7 & & 0.4 & 3 \\
\hline
\end{tabular}


Table 1 (continued)

Frequency of occurrence reflects the number of stories coded with each theme. Agreement shows the percent of stories coded identically across coders. Themes appearing in the EDF email prompts are noted as appearing in the first, second, or both emails

\section{Qualitative analyses}

\section{Factor analysis}

To statistically identify relationships among these coded themes based on their co-occurrence in the stories, we conducted a factor analysis on all 43 coded themes using Principal Components Analysis (PCA). We examined an eigenvalue scree plot to determine the point of deflection that indicates a switch from explaining more to less variance. Based on this, we extracted a 5-factor solution that explained $25 \%$ of the variance, with Promax rotation (allowing individual factors to be correlated with each other). We report all themes loading over 0.5 on each of the five factors. We then averaged all themes loading $>0.5$ for a single composite score to represent each of the five PCA factors in correlational analyses.

\section{Correlational analyses}

Our quantitative analysis plan included statistical tests to identify correlations among all observed themes, PCA composite factors, and demographic variables. However, conducting many statistical tests with the full set of 43 themes, five composite factors, and nine demographic variables greatly increases the risk of observing significance by chance (as a "false positive," Type 1 error). To avoid this in our correlational analyses, we limited the number of variables included. We grouped similar themes based on content similarity into 13 theme clusters (shown in Appendix C), each of which occurred in more than 10\% of stories. The few themes that fell into more than one cluster (e.g., personal experience with migration was included in both the Migration and Personal experiences theme clusters) were removed from both to avoid artificially inflating those correlations. Thus, tests of association were conducted for the five identified composite factors, 13 theme clusters, and nine demographic variables. Finally, we tested whether the mention of a theme in the EDF email prompts predicted their appearance in people's stories. All correlational analyses used Pearson's $r$ (equivalent to a categorical phi coefficient when both variables are binary; Warner, 2008) and all categorical variables were considered with t-tests.

\section{Results}

\section{Frequency of observed themes}

The 691 submitted stories averaged 453.66 characters $(\mathrm{SD}=391.90)$ (approximately 80 words). While the stories posted on the webpage were fairly short, they included (on average) around 7 coded themes $(M=7.29 ; \mathrm{SD}=3.55)$. As shown in Fig. 2, the set of stories ranged from 11 stories with only a single theme to one story including 21 themes. The longest story (792 words, 4422 characters) is shown in Appendix B.

Many of the most common coded themes were mentioned in one or both EDF emails, including beauty, planting milkweed, personal experiences, and knowledge of 


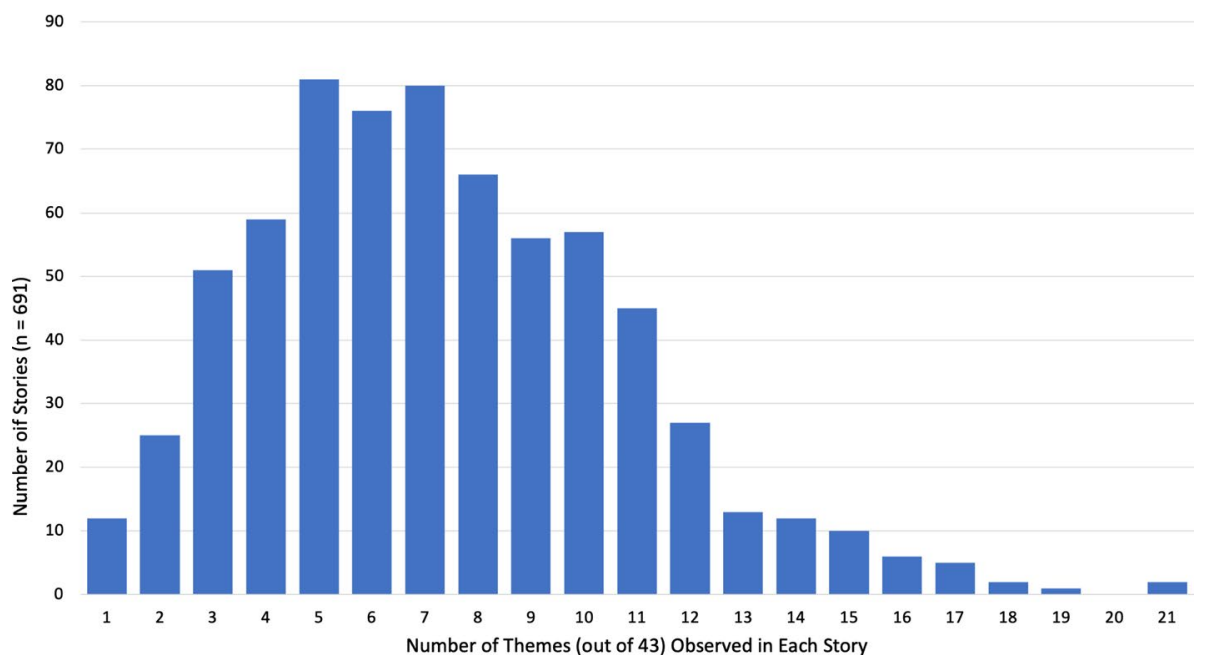

Fig. 2 Frequency distribution with number of themes (out of 43) coded in each submitted monarch story

metamorphosis, migration, and reduction (see Appendix $\mathrm{C}$ for a complete list). The frequency of these email mentions $(0,1,2)$ was correlated with their presence in people's monarch stories, $r(43)=0.47, p<0.01$. Even so, over half of the coded themes emerged without any prompting in emails. These novel themes included personal experiences in home gardens and yards, monarchs alighting on oneself or other people, and its role as a harbinger of other negative environmental changes, as well as being fragile, precious or treasured, as suggested by theories of altruism that derive from caregiving (Preston 2013).

In Table 1, the 43 coded themes are shown with their frequency of occurrence across stories, rank order of frequency, and interrater agreement for each theme.

The most frequent theme reported (of the 43 identified) was beauty, observed in over $35 \%$ of stories. The beauty of the monarch species was mentioned in a much higher proportion of stories than any other individual theme. For example, one story was simply, "The monarch to me represents an iconic image of nature and beauty." Across many themes, conservation concerns were reported, with planting to feed the monarchs mentioned in over $25 \%$ of stories; for example, "I love butterflies and have milkweed, butterfly weed, butterfly bushes and many other butterfly happy plants in my 2-acre yard with fruit orchard in the hills south of Syracuse NY. I do not use pesticides." Other conservation themes were personal experiences observing monarch reduction (17\%):

I love the beauty of the Monarchs. Every year I see less and less of them in my yard which breaks my heart. I try to plant flowers that are butterfly and bee friendly. I let the milkweed grow and spread in my yard.

A subset of these conservation stories admonished human actions (e.g., corporate greed, pesticides, harbinger of broad decline), and described the monarch as a proverbial "canary in a coal mine." Moreover, even though most stories included positive emotions (83\%), some of these stories also expressed anger at the actions of corporations and practices related to farming. For example: 
Living in rural Massachusetts in the 1950s, there were other butterflies to see, but the Monarch was always the most awesome. What losing the Monarch means to me is that we have finally lost...the greed of the companies that only want to rape the land, the animals for profit. They've been allowed or bribed their way into winning...not just in the USA. I think the use of glyphosphate is just too pervasive, but we don't seem to be able to stop it here. I'm just sad and feel that the Monarch is another "canary" to show that living things are being killed off.

For the majority of contributors, writing "your Monarch Story" drew people in to write first-hand accounts of their personal experiences with the species. These themes emphasized personal encounters with monarchs, reflected in the $3 \mathrm{rd}$ most frequent theme of Childhood memories (23\%) in many contexts (e.g., in the yard, at school, during migration):

When I was in second grade, I found a monarch egg on a milkweed leaf, so I brought it home and raised the caterpillar. I named it Tracy because that is a gender-neutral name. When Tracy emerged as a butterfly, I found it was a female. I let her go back into nature and then prepared a timeline of her life to present to my classmates. It was a big hit.

Adult experiences were also frequently reported:

One of the most moving experiences in my life was going to El Rosario Monarch Butterfly Preserve in Mexico where monarch butterflies overwinter. So rarely do we see such an assemblage of so many individuals of one species in such a tiny area. The trees were completely ornamented with monarch butterflies. When the monarchs would take flight, it was like being in an orange and black blizzard. So infrequently do wildlife interact with us humans other than by turning tail and running, but I had multiple monarchs alight on my arms and head. This experience wasn't just moving, it was life-defining.

The 4th most frequent theme was positive emotions (22\%), including joy, happiness, delight; for example, "I worked at a domestic violence shelter, and every year one beautiful monarch would visit the garden, and it brought me such happiness! Imagine what a multitude would do." The stories also frequently expressed a sense of awe and magic arising from monarch encounters:

I just remember that as a child I would see lots and lots of Monarchs passing through our city of Covina, CA each year and I always marveled at their ethereal, colorful beauty. It was somehow awe-inspiring and almost magical. Fast forward 50 years and I'm lucky if I see more than a handful each year. A world without Monarchs altogether would be a world lacking their magic and that would be sad indeed.

Many stories reflected species-specific qualities such as metamorphosis and mass migration; for example:

Monarch butterflies are beautiful, amazing creatures - but strangely they always remind me of my brother Dan. I was riding with my sister and brother-in-law in South Dakota from my brother's wedding to his reception when we saw a flock of monarch butterflies, and my brother-in-law explained to me their amazing migration habits. I realized that they're not only beautiful and fragile, but also strong in many ways. Actually, just seeing one makes me smile. 
The monarch's important role in the ecosystem as a pollinator and sign of ecological balance was also reflected in the stories:

I live in GMO farming country. We no longer have common brown bats, wild honey bees, little milkweed either. Last year my wife and I planted a pollinator garden and half of it was planted with milkweed that I started from seed. We were pleasantly surprised, having only seen 2 monarchs all summer, to witness the formation of 12 chrysalis under our shed eave and all 12 hatched. HABITAT IS EVERYTHING WHEN IT COMES TO NATURE! If you plant it they will come. We also were successful in convincing one landowner to plant timothy hay rather than GMO crops on his leased land. We will continue the good fight and yes the pollinator garden has already been expanded.

While these most frequent themes represent commonalities in the stories, many other themes emerged to reflect a great diversity among the submitted stories. Some included figurative references to the monarch's association with freedom (8\%) and springtime (7\%), spirituality (4\%), and its value as an artistic symbol (appear in art or poems, 2\%). Other stories captured stories about missing loved ones $(5 \%)$, reflecting loss or remembrance of a loved one when seeing a Monarch:

My story starts with when my mother passed. I watched her body transform into the spirit. After her death the monarch butterfly would often fly in circles around me reminding me of her transformation with her spirit and presence changing from this shell she lived in as the butterfly transforms into a new form.

Though submitted on a public website, the recorded stories are striking in their revelation of personal, heart-felt memories and experiences, specific knowledge about monarchs, and concern for conservation efforts on their behalf. The wealth of specific associations in the submitted monarch stories suggests monarch are a touchstone in the story writers's lives over time.

\section{Factor analysis of observed themes}

The 43 themes resulted in a five-factor solution from the Principal Components Analysis (PCA) with four factors including three subsumed themes and one factor including only one theme (see Table 2). We labelled the extracted factors as: (1) Raising Monarchs, with themes about raising butterflies (10), personal experiences with metamorphosis (7), and learning in science classes and schools (32); Denounces Reduction, with themes of loss and sadness over reduction (9), anger about greed and influence of corporations (33) and money interests; 3) Awe at Migration, with themes of awe and wonder (5), personal experiences with massing monarchs (8) and migration (12); (4) Planting Milkweed, with a single theme of planting to feed butterflies (2); and 5) Species Attributes, with themes of strength (e.g., resilience and perseverance) (36), amazing abilities (e.g., "incredible") (30), and fragility (e.g., "delicate") (28).

Among these five composite factors, Raising Monarchs and Planting Milkweed $(r=0.14, p<0.001)$ were positively correlated, as might be expected. Awe at Mass Migration increased with mentions of Species Attributes $(r=0.11, \mathrm{p}<0.01)$ and decreased with mentions of Raising Monarchs $(r=-0.09, p<0.05)$ and Planting Milkweed $(r=-0.17$, $p<0.001)$. No other significant correlations were observed. 


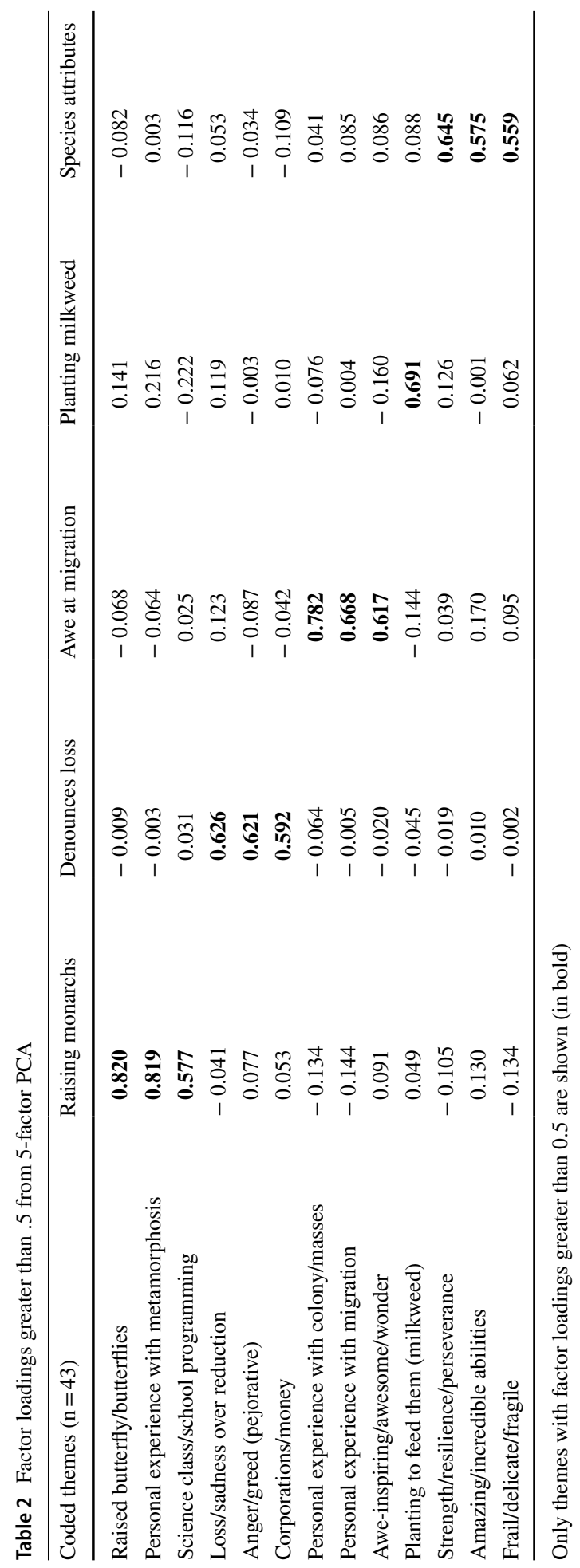




\section{Correlational analyses with theme clusters}

Next, we examined intercorrelations for the 13 theme clusters (compiled from the 43 observed themes). To predict conservation efforts, we focused on three theme clusters describing motivations and actions directed toward monarch conservation: Calls to act, Working to save, and Distress at loss. The Calls to act theme cluster stories spoke out about the need for collective action:

Butterflies are magical to me. Every single time I see one, I smile. I absolutely love them and the habitat loss due to increased use of pesticides must stop immediately.

Stories including the Working to save theme cluster included actions such as planting:

We have planted a demonstration Pollinator Meadow on our complex of 142 acres and have distributed over two hundred milkweed plants to residents for their own gardens and planters. Also, we have encouraged our grounds staff to stop cutting back wild milkweed where ever possible when they manicure the grounds.

About a third of the stories expressed Distress at loss from monarch reduction; for example, "There used to be a lot of butterflies and bees around. I do not see any more. Scary!" We tested whether each of these three conservation themes were associated with one another and the remaining theme clusters (see Table 3).

Several significant associations were revealed among the three conservation-related theme clusters and with the remaining clusters. Stories expressing Distress at loss and Calls to act were positively correlated $(r=0.13, p<0.001)$, and both mentioned Role in the ecosystem more often, suggesting that more knowledge about broader environmental issues is tied to both. The conservation theme of Working to save the monarch was predicted by both Personal experiences and Positive emotions; however, Working to save stories were less likely to also mention Calls to act and were unrelated to Distress at loss. A potential explanation for the inconsistent relationship between conservation themes is the negative spillover effect (Raimi 2017), whereby people who take one type of active response to an environmental concern are less enthusiastic about supporting larger policy or systemic solutions.

Table 3 Intercorrelations with three conservation theme clusters

\begin{tabular}{lll}
\hline Theme cluster & Positive links & Negative links \\
\hline Distress at loss & Species knowledge $\left(r=0.20^{* * *}\right)$ & Missing loved ones $\left(r=-0.10^{* *}\right)$ \\
& Role in ecosystem $\left(r=0.23^{* *}\right)$ & Personal experiences $\left(r=-0.20^{* * *}\right)$ \\
& Calls to act $\left(r=0.14^{* * *}\right)$ & Positive emotions $\left(r=-0.11^{* *}\right)$ \\
Calls to act & Aesthetic beauty $\left(r=0.09^{*}\right)$ & Missing loved ones $\left(r=-0.08^{*}\right)$ \\
& Role in ecosystem $\left(r=0.15^{* * *}\right)$ & Personal experiences $\left(r=-0.11^{* *}\right)$ \\
& Distress at loss $\left(r=0.14^{* * *}\right)$ & Working to save $\left(r=-13^{* * *}\right)$ \\
Working to save & Personal experiences $\left(r=0.13^{* * *}\right)$ & Aesthetic beauty $\left(r=-0.17^{* * *}\right)$ \\
& Positive emotions $\left(r=0.13^{* *}\right)$ & Awe \& magic $\left(r=-0.13^{* * *}\right)$ \\
& & Calls to act $\left(r=-0.13^{* * *}\right)$
\end{tabular}

Significance levels for tests: $* p<0.05 ; * * p<0.01 * * * p<0.001$. Only significant tests are shown 
Table 4 Demographic relationships with 13 theme clusters and 5 composite factors

\begin{tabular}{ll}
\hline Factors and themes & Associations \\
\hline Species qualities & Homeowners $\left(r=.10^{*}\right)$ \\
Aesthetic beauty & Females $\left(t(360)=3.13^{* *}\right)$, Education $\left(r=-0.10^{*}\right)$, Donations $\left(t(512)=1.86^{*}\right)$, \\
& Lifetime Givers $\left(r=-0.10^{*}\right)$, Homeowners $\left(r=.10^{*}\right)$ \\
Metamorphosis & Females $\left(t(360)=2.70^{* *}\right)$ \\
Positive emotions & Females $\left(t(360)=2.33^{*}\right)$ \\
Calls to act & Females $\left(t(360)=1.95^{*}\right)$ \\
Awe at mass migration & Age $\left(r=.12^{* *}\right)$, Income $\left(r=.09^{*}\right)$, Net worth $\left(r=.15^{* *}\right)$, Lifetime Donations \\
Migration & $\left(r=.11^{*}\right)$ \\
Awe \& magic & Age $\left(r=.14^{* *}\right)$, Education $\left(r=.11^{*}\right)$, Donations $\left(r=.10^{*}\right)$, Lifetime Givers \\
Raising monarchs & Income $\left(r=.12^{* *}\right)$ \\
Planting milkweed & Gender $($ Female $)\left(t(360)=2.53^{*}\right)$ \\
Homeowners $\left(t(494)=4.12^{* * *}\right)$, Net Worth $\left(r=.10^{*}\right)$, Lifetime Givers \\
Working to save & $\left(t(512)=2.57^{*}\right)$ \\
Denounce reduction & Age $\left(r=.10^{*}\right)$, Homeowners $\left(t(494)=2.58^{*}\right)$, Lifetime Givers $\left(t(512)=2.36^{*}\right)$ \\
Distress at loss & Location $($ Rural $)\left(r=.12^{* *}\right)$ \\
\hline
\end{tabular}

Theme clusters are listed in italics, PCA factors in bold. Significance levels: $* p<0.05 ; * * p<0.01$. Negative associations are underlined. Non-significant $(p>0.05)$ results are omitted

\section{Relationships with demographic variables}

Finally, we tested for correlations between the nine demographic variables (Table 4) and the five composite factors and 13 theme clusters.

Several patterns of associations with attributes of the story writers emerged across these correlational analyses. The majority of story writers were women, and they were more likely to mention the special qualities of the monarch species, its beauty, their experiences raising monarchs and positive emotions about them. This group was also more likely to call for collective action to save the monarch. Mentions of monarch beauty were less frequent for those with more education and more donation history.

A second pattern of association centered on descriptions of personal awe at mass migration. This theme was more likely for older, more educated writers with higher incomes and net worth, and more donation history (number of gifts and dollars). Older respondents may more frequently discuss mass migration because it was easier to experience before recent reduction. This association is reflected in both the factor scores and the migration theme cluster, and the size of the correlations are larger than for other patterns.

A third pattern groups writers reporting experiences of raising monarchs, planting milkweed, and working to save the monarch. These stories are associated with older, female, and more affluent homeowners who are already active donors. This pattern may reflect those interested and able to manage garden projects to support monarchs.

A final pattern associates stories expressing distress at the loss of monarchs and denouncing their reduction with writers in rural areas. A higher likelihood of seeing natural populations of monarchs may have made rural residents better able to personally note the current reduction in monarch populations. Interestingly, these patterns appear distinct; for example, the mass migration factor is negatively related to raising and planting for 
monarchs, and the Call to action theme cluster is negatively related to Working to save monarchs. While the demographics suggest different uses of themes based on story writer characteristics, the small size of the correlations suggests there are many overlaps in story themes across demographic categories.

In sum, both quantitative and qualitative analyses identified monarch-specific qualities (e.g., metamorphosis, milkweed, migration, and species attributes) together with concern for their conservation as prominent themes. The qualitative analysis offers additional information about what story writers think about monarchs; notably, many describe personal experiences as adults and in childhood memories, along with strong emotions and with the appeal of the monarch's beauty. Interestingly, different patterns of association occurred for writers reflecting distress at monarch loss with calls for action compared to those with higher donations. Those with more resources included a pattern of personal efforts such as planting milkweed while others were monarch enthusiasts who were not engaged in conservation actions. The mixed methods approach in our study utilized qualitative analysis of themes to suggest meaning behind the findings from quantitative methods, producing a richer account of people's monarch stories contributed to the campaign.

\section{Discussion}

Whereas previous empirical studies compared perceptions of flagships across species (Caro et al. 2004; Schlegel and Rupf 2010; Barua 2011; Barua et al. 2012; Roberge 2014; MacDonald et al. 2015), this study is the first to examine people's in-depth responses to a single flagship species both qualitatively and quantitatively. The results show that monarch butterflies have special appeal that differs among individuals. Taking a broad perspective, distinctive patterns of relationships in theme clusters, factors, and demographic variables are evident across the Monarch Stories. These patterns emerge from considering the intercorrelations among the five identified PCA factors (Table 2), the theme clusters arising from the qualitative analysis (Table 3), and the significant correlations with demographic variables (Table 4). These patterns suggest that groups of Monarch Story contributors differed in the qualities emphasized in their stories and in their conservation actions.

\section{The role of personal connection}

The finding that personal encounters with monarchs powerfully influence conservation themes is consistent with Bandura's $(1999,2018)$ theory of motivation tying personal experiences to people's later actions. That is, people's conservation interests and actions may reflect their acquired, self-relevant learning experiences. Many people living in the U.S. have personal memories of monarch encounters, along with childhood memories about caring for monarchs from school programs (Young-Isebrand et al. 2015; Gustafsson et al. 2015). People's responses to monarch reduction may also be structured by shared cultural history and associations (DeMello 2012; Jepson and Barua 2015; Gustafsson et al. 2017) and place-specific ties (Jepson and Barua 2015; Horsley et al. 2020) to their experiences. Early positive experiences may motivate later conservation interest and actions (see Bandura 2018).

The monarch stories also describe powerful feelings associated with monarchs, such as "joy," and "awe," as in a sense of wonder and magic, along with other attributes like strength and perseverance (Gustafsson et al. 2015; Simaika and Samways 2018). 
Encounters with monarchs may thus lead to more intimate emotional connections to them based on their familiarity from experience (Schlegel and Rupf 2010; Macdonald et al. 2015). Studies have shown a link between positive feelings of awe and intentions (Keltner and Haidt 2003), and awe toward nature leads spiritual people to express feelings of oneness with others (Van Cappellen and Saroglu 2012). Awe has also been shown to serve as a precursor to science learning (Valdesolo et al. 2017), so the pervasive presence of awe around mass migration may elicit openness to learning, as documented by the frequent descriptions of learning about monarchs in the stories. Awe has also been associated with altruism (Stellar et al. 2017), suggesting that awe might promote interest and giving to environmental campaigns.

Altruistic themes in the monarch stories - a novel finding-emerged as many stories focused upon current caretaking actions for monarchs, such as planting milkweed to feed them, raising monarchs through their early life cycle, joining conservation monitoring groups and volunteering to help them. These results are consistent with theories of altruism related to caregiving (Preston 2013), which predict that people are motivated by a perceived need to care for attractive, vulnerable others in immediate need. Females as a demographic group also more often mentioned raising butterflies, planting milkweed, and the need for action, consistent with this theory. Lewandowski and Oberhauser (2017) found that monarch waystation volunteers planned to donate at the same or higher levels afterwards, further indicating that altruistic conservation actions and donations are related. The identification of needs and the provision of first-hand support for the species may be more appealing for those with caregiving motivations and may remain unfulfilled by other forms of altruism, such as financial donations toward land conservation. Further, asking contributors to identify their current conservation actions may increase awareness of potential "negative spillover" (Raimi 2017), wherein people may react to proposed environmental interventions with their own, individual efforts in front of mind.

\section{Implications}

This study may offer insights for future conservation campaigns. While previous studies found that people prefer larger, charismatic mammals (Schlegel and Rupf 2010, Barua 2012; Roberge 2014; Macdonald et al. 2015, 2017) with aesthetic appeal (Smith et al. 2012), our findings documented people's positive feelings for an insect. Though Schlegel and Rupf (2010) had found that butterflies were preferred even over mammals, invertebrates are rarely selected as flagship species. Our study found evidence that monarchs draw people in to respond to their conservation needs based upon the monarch's beauty, the emotions they evoke, their familiarity, and memories of positive personal encounters. Monarchs also feature distinctive species attributes that are observed in school programs, citizen science projects, and cultural communications. Moreover, based upon these early experiences, many people are already knowledgeable about and interested in monarch conservation that, as Bandura (2018) argues, may establish a motivation to engage in their conservation. A challenge for future research is to identify other species with similar personal and experiential ties within other regional populations.

An important implication of this study is that personal, direct experiences with a flagship species may motivate later action. The monarch's accessibility in the U.S. seems a key factor in their appeal: currently, people are still encountering monarchs in their gardens, parks, and schools (or noting their absence). Often, conservation campaigns are planned from the reverse direction: they provide new information to stir emotions in order 
to motivate people to act. Our findings suggest that conservation programs might instead engage people in conservation actions first in order to build awareness, positive feelings, and personal memories. Experiences occurring as precursors may build the link to later conservation actions like making donations. Positive experiences (e.g., studying monarchs in grade school) can be strong motivators in and of themselves, and can stimulate a positive link between emotions, awareness and further conservation actions (Singleton 2016).

Conservation campaigns may promote this by providing opportunities to interact with species first-hand, creating personal knowledge and experiences with specific species encountered in local areas. Segmenting campaigns to highlight species encounters based on geographic region may be better able to build more personal experiences and commitment. Increasing animal contact for children has been shown to increase propensity for biophilia and decreases biophobia, along with enhancing pro-conservation attitudes (Zhang et al. 2014). Our findings suggest that adult groups may also benefit from continued encounters with local species, helping people remain engaged and informed about why and how to be active in the process of their conservation. In particular, the themes that center around caretaking, such as raising monarchs and helping animals in need, may elicit support from people who are motivated by nurturing in ways that are unfulfilled by financial donations.

While many species are now difficult to encounter in the wild, technological advances may increase exposure and familiarity; for example, people can see what an animal sees in the field through animal-borne video and environmental data collection systems (AVEDs) (Moll et al, 2007), and camera trap technology may allow even real-time observations of threatened species by the public (Belbachir et al. 2015). Opportunities through social media campaigns offer new ways of engagement with more region- or interest-specific encounters. For environmental organizations, engaging donors and program stakeholders in interconnected actions over time may increase commitment and investment (Lewandowski and Oberhauer 2017). Developing public engagement campaigns that are "personal" may prove instrumental in reaching a common goal to preserve biodiversity.

This study also highlights the importance of learning more about differences in people's responses to flagship species in order to more effectively incorporate them into conservation campaigns. Are species attributes (beauty or mass migration) or experiences with them (near home, "hands-on") more important to individuals? If positive experiences and personal memories are most impactful, campaigns can be designed with regional foci leading to greater personal investment in engaging, helping, and donating on behalf of a species. Appreciation of animals is constructed within a sociocultural milieu (Gustafsson et al. 2017), with positive cultural associations shaped by history and the specifics of place (Jepson and Barua 2015). DeMello (2012) stressed the importance of the spaces animals occupy in human social and cultural worlds, and the interactions humans have with them. Further research should explore how people within regional cultures respond to specific species, and what kinds of experience-based learning methods inspire people to make the leap from awareness to understanding to action.

These findings support the claim by Gustafsson and colleagues $(2015,2017)$ that the monarch has been perhaps uniquely positioned over many years to serve as a symbol for conservation in the U.S. (Gustafsson et al. 2015). For those responding to the EDF's Monarch Stories campaign, the monarch's beauty, natural wonder in mass migration, and familiarity from individual encounters has led to deep ties and a strong motivation to help them. In future studies, ENGOs willing to provide data from campaigns may document the relationships to flagship species suggested in this study. Considering flagship-specific data may support innovative social media campaigns and identify alternate forms of engagement that are effective for distinct groups of donors. 
Finally, a key finding emerging from the monarch stories was the emotion reflected in people's stories about individual monarchs. Conservation organizations may avoid emotional appeals because they seem "alarmist" or too "touchy-feely" for science-based programs. Yet in this study, deep emotions arising from precious memories were readily offered by the public engaging in the campaign. Our study suggests that conservationists should seek to evoke, not avoid, emotion as part of conservation campaigns in order to motivate action. Nuanced communication that weaves meaningful emotional experiences into science-based appeals may increase the effectiveness of conservation campaigns.

EDF's Monarch Stories Campaign included innovations that successfully engaged their members. By seeing a personal story from EDF staff in an email, people were "primed" to discuss both the same and novel topics in their own stories. These social interactions may serve to scaffold the development of people's views of conservation, increasing their sense of community and commitment to environmental concerns. And their novel approach of asking, "What does the Monarch mean to you?" encouraged people to think about a conservation issue as their personal concern. This low-investment activity may be an effective means of drawing people into the campaign and the EDF website, influencing their further interaction with organizational materials and potentially their financial support for the campaign.

\section{Limitations}

This mixed methods study investigated a single campaign as a case study with an interpretivist epistemological perspective (Flyvbjerg 2001, 2006; Patton 2002) where the outcomes depend on the context, and the context is integrated into the analysis of findings (Creswell 1994; Patton, 2002). The outcomes are not intended for generalization across campaign contexts differing substantially from this case. Our findings are strictly associational, and no causal conclusions can be drawn. While the associations reported are statistically significant, most account for only a small proportion of the variance; for example, the positive correlation between the theme clusters, "distress at loss" and "role in the ecosystem" accounts for approximately five percent of the variance. However, across a large sample of potential donors, small influences leading individuals to act are of practical significance.

Available demographic information for the sample was also limited, and participants were existing members at EDF (likely to be U.S. residents, already committed to conservation, and interested in EDF's pragmatic and solutions-focused approach). As noted above, the campaign materials included two example stories with themes that appeared often in the collected stories; however, more than half of the themes observed were not mentioned at all in EDF materials.

\section{Conclusion}

Overall, our findings show that people share awe-inspired, joyous memories of their personal encounters with beautiful monarchs. However, this experiential point of contact may be only infrequently engaged when designing conservation campaigns. Selecting flagship species for campaigns by assessing preferences in the abstract (Schlegel and Rupf 2010; Verissimo et al. 2011; MacDonald et al. 2015; Tensen 2018) may fail to capture the strong draw of lived experiences with specific species in local environments. Drawing on personal 
experiences with wildlife builds awareness and associations with species that may increase later motivation to help in their conservation.

As Richard Louv (2005) suggested, childhood experiences in the natural world are predictors of conservation activism in adulthood. In the Monarch Story campaign, a quarter of adults described childhood encounters with monarchs through school programs that predicted their current efforts to save monarchs. Children exposed to monarchs in science classes are not only learning about science: They are also building intimate connections to individual monarchs through personal experiences that echo through encounters with the species throughout their lives. Outreach programs, classes, and field trips foster memorable one-on-one encounters between species, building personal engagement and creating future conservationists.

Supplementary Information The online version contains supplementary material available at https:/doi. org/10.1007/s10531-021-02183-x.

Acknowledgements We thank Audrey Archer at the Environmental Defense Fund for her assistance with data access. We also thank Skylar Burkhardt and Amanda Szczesniak, undergraduate research assistants at the University of Michigan, for their contributions to the project. We are grateful to the Environmental Defense Fund for their willingness to contribute anonymized web page entries and demographic information.

Funding A grant to support data analyses was provided by Environmental Defense Fund and the Graham Sustainability Institute to S. D. Preston and C. M. Seifert at the Department of Psychology, University of Michigan, Ann Arbor.

Data availability Story data is available upon request.

\section{Declarationss}

Conflict of interest Two of the authors (Theodore Toombs and Rainer Romero-Canyas) are currently employed as scientists at the Environmental Defense Fund.

Consent for publication All authors agree.

Open Access This article is licensed under a Creative Commons Attribution 4.0 International License, which permits use, sharing, adaptation, distribution and reproduction in any medium or format, as long as you give appropriate credit to the original author(s) and the source, provide a link to the Creative Commons licence, and indicate if changes were made. The images or other third party material in this article are included in the article's Creative Commons licence, unless indicated otherwise in a credit line to the material. If material is not included in the article's Creative Commons licence and your intended use is not permitted by statutory regulation or exceeds the permitted use, you will need to obtain permission directly from the copyright holder. To view a copy of this licence, visit http://creativecommons.org/licenses/by/4.0/.

\section{References}

Abercrombie N, Hill S, Turner BS, Erofeev SA (1984) The Penguin dictionary of sociology. Penguin, Harmondsworth, UK

Bandura A (1999) Social cognitive theory of personality. Handbook Personal 2:154-196

Bandura A (2001) Social cognitive theory: An agentic perspective. Annu Rev Psychol 52:1-26. https://doi. org/10.1146/annurev.psych.52.1.1

Bandura A (2018) Toward a psychology of human agency: Pathways and reflections. Perspect Psychol Sci 13(2):130-136. https://doi.org/10.1177/1745691617699280 
Barua M (2011) Mobilizing metaphors: the popular use of keystone, flagship and umbrella species concepts. Biodiv Conserv 20:1427. https://doi.org/10.1007/s10531-011-0035-y

Barua M, Gurdak DJ, Ahmed RA, Tamuly J (2012) Selecting flagships for invertebrate conservation. Biodiv Conserv 21:1457-1476. https://doi.org/10.1007/s10531-012-0257-7

Belbachir F, Pettorelli N, Wacher T, Belbachir-Bazi A, Durant SM (2015) Monitoring rarity: the critically endangered Saharan cheetah as a flagship species for a threatened ecosystem. PLoS One, 10(1)

Bennett JR, Maloney R, Possingham HP (2015) Biodiversity gains from efficient use of private sponsorship for flagship species conservation. Proceed Royal Soc B: Biol Sci 282(1805):20142693

Boeije H (2002) A purposeful approach to the constant comparative method in the analysis of qualitative interviews. Qual Quant 36(4):391-409

Born D (2019) Bearing witness? Polar bears as icons for climate change communication in National Geographic. Environ Commun 13(5):649-663

Caro T, Engilis A Jr, Fitzherbert E, Gardner T (2004) Preliminary assessment of flagship species concept at a small scale. Anim Conserv 7:63-70

Creswell JW (1994) Research design: Qualitative and quantitative approaches. Sage, Thousand Oaks, $\mathrm{CA}$

Creswell, J. W. (2017). Research design: Qualitative, quantitative, and mixed methods approaches. Sage Publications.

DeMello M (2012) Animals and society: an introduction to human-animal studies. Columbia UP, New York

Douglas LR, Winkel G (2014) The flipside of the flagship. Biodivers Conserv 23(4):979-997

Environmental Defense Fund (2018). Monarch stories. https://www.edf.org/what-you-can-do-helpMonarchs. 12 Jan 2018

Environmental Defense Fund (2020). Why we need a variety of ways to protect wildlife. https://www. edf.org/ecosystems/why-we-need-variety-ways-protect-wildlife. 25 March 2020

Flyvbjerg B (2001) Making social science matter: Why social inquiry fails and how it can succeed again. Cambridge University Press, Cambridge, UK

Flyvbjerg B (2006) Five misunderstandings about case-study research. Qual Inq 12(2):219-245

Flyvbjerg B (2011) Case study. In: Denzin NK, Lincoln YS (eds) The Sage handbook of qualitative research, 4th edn. Sage, Thousand Oaks, CA, pp 301-316

Greene RW, Shepard J (2003) Sociology and you. Glencoe Mc Graw-Hill, Ohio, pp A-22

Gustafsson KM, Agrawal AA, Lewenstein BV, Wolf SA (2015) The monarch butterfly through time and space: The social construction of an icon. Bioscience 65(6):612-622

Gustafsson KM, Agrawal AA, Wolf SA (2017) Science-policy-practice interfaces: emergent knowledge and monarch butterfly conservation. Environ Policy Gov 27:521-533

Horsley S, Hohbein R, Morrow K, Green GT (2020) What's in a name? A content analysis of environmental NGOs' use of “iconic species” in press releases. Biodiv Conserv 29:2711-2728. https://doi. org/10.1007/s10531-020-01995-7(0123456789

Jepson P, Barua M (2015) A theory of flagship species action. Conserv Soc 13(1):95-104

Keltner D, Haidt J (2003) Approaching awe, a moral, spiritual, and aesthetic emotion. Cogn Emot 17(2):297-314

Lemelin RH, Jaramillo-López PF (2019) Orange, black, and a little bit of white is the new shade of conservation: the role of tourism in Monarch Butterfly conservation in Mexico. J Ecotourism 1-13.

Lemelin RH, Boileu EYS, Russell C (2019) Entomotourism: the allure of the arthropod. Soc Anim 27:733-750

Lewandowski EJ, Oberhauser KS (2017) Contributions of citizen scientists and habitat volunteers to monarch butterfly conservation. Hum Dimens Wildl 22(1):55-70. https://doi.org/10.1080/10871 209.2017.1250293

Louv R (2005) Last child in the woods: Saving our children from nature-deficit disorder. Workman Publishing Company, New York

Macdonald EA, Burnham D, Hinks AE, Dickman AJ, Malhi Y, Macdonald DW (2015) Conservation inequality and the charismatic cat: Felis felicis. Global Ecol Conserv 3:851-866

Macdonald EA, Hinks A, Weiss DJ, Dickman A, Burnham D, Sandom CJ, Macdonald DW (2017) Identifying ambassador species for conservation marketing. Global Ecol Conserv 12:204-214

McGinlay JM, Parsons DJ, Morris J, Hubatova M, Graves A, Bradbury RB, Bullock JM (2017) Do charismatic species groups generate more cultural ecosystem service benefits? Ecosyst Serv 27A:15-24

Moll RJ, Millspaugh JJ, Beringer J, Sartwell J, He Z (2007) A new 'view 'of ecology and conservation through animal-borne video systems. Trends Ecol Evol 22(12):660-668

Monarch Joint Venture (2020). About Us. https://Monarchjointventure.org/. 27 March 2020

Nail KR, Altizer S, Oberhauser KS (2015) Monarchs in a changing world: Biology and conservation of an iconic butterfly. Cornell University Press, United States 
Oberhauser KS, Nail KR, Altizer S (Eds) (2018) Monarchs in a changing world: biology and conservation of an iconic butterfly. Cornell University Press

Patton MQ (2002) Qualitative evaluation and research methods, 3rd edn. Sage, Thousand Oaks, CA

Preston SD (2013) The origins of altruism in offspring care. Psychol Bull 139(6):1305-1341. https://doi. org/10.1037/a0031755

Raimi K (2017) Negative spillover to policy. Nat Clim Change 7:473-474. https://doi.org/10.1038/nclim ate 3317

Roberge JM (2014) Using data from online social networks in conservation science: which species engage people the most on Twitter? Biodivers Conserv 23(3):715-726

Schlegel J, Rupf R (2010) Attitudes towards potential animal flagship species in nature conservation: a survey among students of different educational institutions. J Nat Conserv 18(4):278-290

Simaika JP, Samways MJ (2018) Insect conservation psychology. J Insect Conserv 22:635-642. https:// doi.org/10.1007/s10841-018-0047-y

Simberloff D (1998) Flagships, umbrellas, and keystones: Is single-species management passe in the landscape era? Biodivers Conserv 83:247-257

Singleton, J. (2016). Environmental literacy and sustainability values: A content analysis of environmental education standards. ECO-THINKING, 1. https://eco-thinking.org/index.php/journal/article/view/984

Smith RJ, Verissimo D, Isaac NJB, Jones KE (2012) Identifying Cinderella species: uncovering mammals with conservation flagship appeal. Conserv Lett 5:205-212

Stellar JE, Gordon AM, Piff PK, Cordaro D, Anderson CL, Bai Y, Maruskin LA, Keltner D (2017) Selftranscendent emotions and their social functions: compassion, gratitude, and awe bind us to others through prosociality. Emot Rev 9(3):200-207

Tensen L (2018) Biases in wildlife and conservation research, using felids and canids as a case study. Global Ecol Conserv 15:e00423. https://doi.org/10.1016/j.gecco.2018.e00423

Thogmartin WE, Wiederholt R, Oberhauser K, Drum RG, Diffendorfer JE, Altizer S, Taylor OR, Pleasants J, Semmens D, Semmens B, Erickson R, Libby K, Lopez-Hoffman L (2017) Monarch butterfly population decline in North America: identifying the threatening processes. Royal Soc Open Sci 4(9):170760. https://doi.org/10.1098/rsos. 170760

Thomas-Walters L, Raihani NJ (2017) Supporting conservation: the roles of flagship species and identifiable victims. Conserv Lett 10(5):581-587. https://doi.org/10.1111/conl.12319

Urquhart FA, Urquhart NR (1976) The overwintering site of the eastern population of the monarch butterfly (Danaus P. Plexippus; Danaidae) in southern Mexico. J Lepidopterists' Soc 30:153-158

Valdesolo P, Shtulman A, Baron AS (2017) Science is awe-some: the emotional antecedents of science learning. Emot Rev 9(3):215-221

Van Cappellen P, Saroglou V (2012) Awe activates religious and spiritual feelings and behavioral intentions. Psychol Relig Spiritual 4(3):223

Verissimo D, MacMillan DC, Smith RJ (2011) Toward a systematic approach for identifying conservation flagships. Conserv Lett 4:1-8

Warner RM (2008) Applied statistics: From bivariate through multivariate techniques. Sage, New York

The White House (2014) Presidential memorandum -- Creating a federal strategy to promote the health of honey bees and Other pollinators. Office of the Press Secretary. https://obamawhitehouse.archives. gov/the-press-office/2014/06/20/presidential-memorandum-creating-federal-strategy-promote-healthhoney-b. 20 June 2014

World Wildlife Fund (2020). Adopt a polar bear. https://www.worldwildlife.org/species/polar-bear. 1 June 2020

Young-Isebrand, E., Oberhauser, K. S., Bailey, K., Charest, S., Hayes, B., Howard, E., Lovett, J,, Meyers, S., Mollenhauer, E., Montesiños-Patino, E. B., Ryan, A., Taylor, O. R., \& Treviño, R. (2015). Environmental education and monarchs: Reaching across disciplines, generations, and nations. In K. S. Oberhauser, K. R., Nail \& S. Altizer (Eds.). (2015). Monarchs in a changing world: Biology and conservation of an iconic butterfly (pp. 5-12). Cornell University Press.

Zhang W, Goodale E, Chen J (2014) How contact with nature affects children's biophilia, biophobia and conservation attitude in China. Biol Cons 177:109-116

Publisher's Note Springer Nature remains neutral with regard to jurisdictional claims in published maps and institutional affiliations. 